\title{
La conformación de la colección folklórica del Instituto de Antropología, Lingüística y Folklore (1941-1956) de la Universidad Nacional de Córdoba, Argentina
}

\author{
[The Conformation of the Folk Collection of the 'Instituto de Antropología, \\ Lingüística y Folklore (1941-1956) de la Universidad Nacional de Córdoba', \\ Argentina]
}

\author{
Agustín Cuevas \\ (Universidad Nacional de Córdoba, Argentina) \\ agustin1cuevas@gmail.com
}

\begin{abstract}
Resumen
En este artículo me propongo historizar la conformación de la colección folklórica de la Reserva Patrimonial del Museo de Antropología de la Universidad Nacional de Córdoba, Argentina, y, particularmente, la sección de musicología: las políticas institucionales que encauzaron estas prácticas de recolección y conformación del acervo, los criterios teóricos y metodológicos implicados en la conformación de la sección musicológica y la trayectoria de esta sección como parte del proceso de puesta en valor de la misma. Partiendo del caso del Instituto de Antropología, Lingüística y Folklore (IALF), y su análisis, se busca aportar a la reflexión sobre la relación entre folklore y nación en el periodo comprendido entre 1941 y 1956.
\end{abstract}

Palabras claves: Conservación Preventiva; Folklore; Nacionalismo.

\begin{abstract}
In this article, the researcher intends to create a historical record of the formation of the folk collection, a part of the Heritage Reserve of the "Museo de Antropología de la Universidad Nacional de Córdoba" (UNC), with a focus on the musicology section: the institutional policies that led to these practices of collection and configuration of the heritage archive; the theory and methodology implicated in the formation of the musicological section; and the trajectory of this section as part of the valuing of the local cultural heritage. This work is based on the case of the "Instituto de Antropología, Lingüística y Folklore" (IALF), and its analysis seeks to contribute to the reflection on the relationship between folklore and national identity, during the period between 1941 and 1956.
\end{abstract}

Keywords: Preventive Conservation; Folklore; Nationalism.

Recibido: 28/02/2020

Evaluación: 17/06/2020

Aceptado: 28/08/2020

Anuario de la Escuela de Historia Virtual - Año 11 - N 18 - 2020: pp. 46-68.

ISSN: 1853-7049

http://revistas.unc.edu.ar/index.php/anuariohistoria 


\section{La conformación de la colección folklórica del Instituto de Antropología, Lingüística y Folklore (1941-1956) de la Universidad Nacional de Córdoba, Argentina}

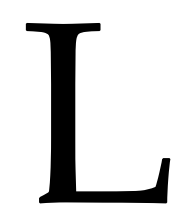

a Reserva Patrimonial es el espacio donde trabajan las áreas de conservación y documentación del Museo de Antropología, perteneciente a la Facultad de Filosofía y Humanidades (FFyH) de la Universidad Nacional de Córdoba (UNC), Argentina. Tiene por función custodiar y realizar tareas de conservación preventiva sobre los objetos antropológicos y la documentación que componen el acervo patrimonial del Museo, mediante tareas de limpieza, acondicionamiento, registro, inventario, catalogación y digitalización. La Reserva se encuentra ubicada en el Pabellón Azul de Ciudad Universitaria y cuenta con un laboratorio, un aula laboratorio, que comparte con la carrera de Antropología, y un subsuelo donde están las áreas de reserva con los materiales y el archivo. Los materiales que se encuentran en este espacio se han ido acumulando a lo largo de más de 75 años, producto de investigaciones, donaciones, compras e intercambios con otras instituciones nacionales y extranjeras. Estos objetos, tanto físicos como digitales, se encuentran disponibles para su investigación y difusión, y son accesibles para ser consultados tanto por públicos universitarios como no universitarios. Actualmente, en este lugar trabajan técnicos, investigadores y becarios de la Universidad y del Consejo Nacional de Investigaciones Científicas y Técnicas (CONICET), así como estudiantes que están realizando sus trabajos finales de grado o que participan en distintos proyectos de investigación. La colección folklórica de la reserva es una de las colecciones fundadoras de lo que actualmente es el Museo de Antropología (MdA) y también una de las más consultadas por investigadores y público en general. ${ }^{1}$

En este espacio realicé prácticas profesionales supervisadas, entre finales de 2017 y principios de 2019, como modalidad de trabajo final de la Licenciatura en Antropología. ${ }^{2}$ Trabajé con noventa y cuatro fichas musicales, noventa y dos numeradas y dos sin

\footnotetext{
${ }^{1}$ A lo largo de este artículo voy a escribir la palabra Folklore respetando la disposición de Viggiano Esaín, folklorista investigador del Instituto de Arqueología, Lingüística y Folklore, que consideraba la postura de los sostenedores de la castellanización de la palabra Folklore un tanto exclusivista, debido a que, para él, una palabra cuya grafía se había generalizado universalmente y que designaba a dicha ciencia con una propiedad que no había hallado equivalente ni sustituto en ninguna otra lengua, debería continuar como, hasta ese momento, porque si se entendía que la base del Folklore es la tradición, era lógico que conservara la tradición de su nombre, como un homenaje a quien la aplicó por primera vez, William John Thoms en 1846, y a la Sociedad de Folklore de Londres (1878), que fue la primera institución que reunió los estudios y a los estudiosos de esta ciencia del mundo entero y confirió carácter científico a esta disciplina (Viggiano Esaín, 1969, p. 14).

${ }^{2}$ El trabajo final de grado fue dirigido por la Dra. Guillermina Espósito y la tutora de las prácticas fue la Lic. Soledad Ochoa.
}

Anuario de la Escuela de Historia Virtual - Año 11 - N 18 - 2020: pp. 46-68. ISSN: 1853-7049 
48 | La conformación de la colección folklórica del Instituto de Antropología...

numerar, ${ }^{3}$ y 15 discos de pasta producto de las recopilaciones de los folkloristas del Instituto de Arqueología, Lingüística y Folklore (IALF) entre 1941 y 1956. Este periodo en concreto enmarca el comienzo de la colección folklórica con la creación del IALF y el final del periodo de recolección de los materiales en el campo por parte de los folkloristas que realizaron las investigaciones, puesto que en 1957 el IALF pasaría a ser el Instituto de Antropología, dejando de lado las investigaciones folklóricas.

En este artículo, me propongo dar cuenta de aquellas directrices que orientaron mi trabajo de prácticas, en relación a este espacio de custodia de materiales, sometido a lo largo del tiempo a sucesivos y diversos criterios de selección, clasificación y ordenamiento. Estos fueron plasmados en el sistema formal de registro de las colecciones del Archivo del Museo de Antropología (AMdA), así como en otro tipo de documentación como la contenida en los archivos administrativos y científicos. Para poder comprender esto, fue de mucha utilidad el concepto de biografía cultural de las cosas planteado por Kopytoff (1991). Dicho concepto alude a la gama de posibilidades biográficas que una determinada sociedad ofrece sobre diversas categorías de objetos y examina el modo en que se realizan esas posibilidades en sus historias vitales. Una biografía culturalmente configurada concibe el objeto como una entidad construida, cargada de significados específicos y clasificada y reclasificada de acuerdo con categorías culturalmente constituidas, correspondiendo al estado físico de la cosa un uso específico en cada periodo. Esto nos permite reconocer como premisa que el objeto musealiza(do)/(ble) y/o patrimonializa(do)/(ble) en el contexto museológico puede haber sido significado en distintos momentos de acuerdo a diversos modos y haber devenido objeto de uno u otro tipo en diversas trayectorias. Este concepto me sirvió para pensar la trayectoria de la colección folklórica en general y la sección de musicología en particular, tanto a partir de las tareas técnicas que realicé en la reserva, como del análisis de documentos ${ }^{5} \mathrm{y}$ publicaciones del IALF del periodo escogido, una entrevista a una exdirectora del MdA y fuentes bibliográficas. A través de esa diversidad de fuentes me fue posible reconstruir, al menos en parte, la biografía cultural de la colección. El proceso de conservación preventiva, que incluye el diagnóstico sobre el estado de conservación de los materiales, me permitió pensar cómo las políticas institucionales afectaron y afectan la materialidad de los objetos desde las concepciones de depósito y reserva que se tuvieron en el pasado y que se manejan en el presente respectivamente. Considero que las intervenciones realizadas durante mis prácticas forman parte de las actuales políticas

\footnotetext{
${ }^{3}$ Estas fichas están compuestas por una partitura y un análisis musical.

${ }^{4}$ Carlos Vega propuso, en 1944, que el folklorista se dedica a estudiar hechos antiguos, tradicionales, arcaicos, extraños, vestigios, supervivencias culturales que se mantienen vivas, los bienes del hombre primitivo, lo que concierne al pasado, las cosas de la edad remota (Vega, 1944, p. 21), a lo que Chamosa (2012, p. 25) agrega que salían al campo en búsqueda de las tradiciones que acreditaban la antigüedad de la nación, aspecto fundamental del reclamo de soberanía. En este artículo, haré referencia de esta forma a los investigadores del Folklore que trabajaron tanto en el IALF, como en otras instituciones del país.

${ }^{5}$ Informes de viaje de los folkloristas, cartas del director del instituto a las autoridades de la Universidad y documentos administrativos que se encuentran en el AMdA.
}

Anuario de la Escuela de Historia Virtual - Año 11 - No 18 - 2020: pp. 46-68. ISSN: 1853-7049 
institucionales, como la puesta en valor de la colección y que estos procesos pasaron ya a ser parte de la trayectoria de la misma.

\section{Conservación preventiva}

La conservación preventiva es la metodología de trabajo que orientó mi intervención en la Reserva del Museo. Esta metodología ayuda a establecer los dispositivos necesarios para prevenir cualquier posible deterioro de los materiales. Se trata de todas aquellas acciones de carácter transversal que tienen como objeto detener o retardar en el tiempo el posible deterioro, creando las condiciones necesarias para preservar los objetos (Portilla Romero, 2014, p. 21). Los técnicos de la Reserva proponen que la disociación es el principal agente de deterioro o pérdida que está afectando a las colecciones actualmente, mientras que el resto de los factores de deterioro de los materiales están controlados, es decir que las colecciones están estabilizadas. ${ }^{6}$ La disociación constituye un agente de deterioro porque implica una pérdida de información, que se subsana con la tarea de documentar y así contextualizar las colecciones. Una de las mayores causas de la disociación corresponde a la sucesión de criterios de trabajo aplicados a los materiales en distintas épocas. Los distintos criterios que se fueron sucediendo a través del tiempo, en muchos casos, no quedaron registrados de manera formal y, por lo tanto, hoy no podemos saber cuáles fueron. Hay datos que se obtienen trabajando con las colecciones, lo cual permite historizar cómo se fueron conformando las mismas, qué objetos se perdieron, cuáles se regalaron o se prestaron a otras instituciones o, incluso, cuáles se llevaron los investigadores. Para ello, se registran los movimientos que hablan de la historia de la colección en sí. Cómo se fue generando, cómo se fue moviendo y, si fue una donación, de dónde provino. Cuando la información se encuentra junto con los materiales, esta se digitaliza y se sube a un repositorio digital. ${ }^{7}$ El registro tiene la importancia de que al historizar los objetos es posible tomar decisiones sobre su exhibición y préstamo.

\footnotetext{
${ }^{6}$ Nos encontramos con un caso de disociación cuando una caja o contenedor presenta cierta información en su etiqueta, pero el contenido no coincide, esto pasa en muchas de las colecciones de la reserva y también con la documentación.

${ }^{7}$ Si bien la Ley nacional 26.899 sobre Repositorios Digitales Institucionales de acceso abierto reglamentada en el año 2016 obliga a los investigadores que realicen trabajos con financiamiento del Estado a depositar las versiones de su trabajo y de sus datos primarios (Izeta et al., 2017, p. 3) en el MdA, la digitalización se viene dando con anterioridad. Desde la primera década del siglo XXI se inició un proceso de conservación y digitalización de las colecciones arqueológicas y etnográficas, y parte de los documentos manuscritos procedentes de campañas arqueológicas o investigaciones realizadas en su ámbito, además de publicaciones históricas y actuales, fueron puestos a disposición permanente de estudiantes e investigadores (Izeta et al., 2017, p. 1).
}

Anuario de la Escuela de Historia Virtual - Año 11 - N 18 - 2020: pp. 46-68. ISSN: 1853-7049 
50 | La conformación de la colección folklórica del Instituto de Antropología...

\section{Del depósito a la reserva patrimonial}

A partir de una entrevista realizada a Mirta Bonnin, directora del MdA durante los periodos 1997/2010 y 2013/2016, fue posible adentrarme en la concepción con la que fue creada la actual Reserva Patrimonial del Museo de Antropología y la diferencia con la antigua concepción de depósito a la que se sometió a las colecciones durante el periodo del Instituto de Arqueología, Lingüística y Folklore entre 1941 y 1957, y el del posterior Instituto de Antropología (IA), entre 1957 y 1987. La importancia de estos cambios de denominación en la institución, que actualmente es el MdA, radica en que no fueron solamente cambios nominales, sino que respondieron a cambios en la política institucional, de la perspectiva con la que se entendía la disciplina antropológica en distintos momentos del tiempo. A su vez, esto repercutió en la trayectoria de la materialidad de los objetos pertenecientes a las colecciones. Ya en la época en la que se creó el IALF, un depósito estaba asociado, en la tradición científica de la antropología y la arqueología, con el lugar donde están situados los materiales que sirven para llevar a cabo las investigaciones. De esta manera, el depósito tenía características más vinculadas con la inmovilidad y solo se interactuaba con él para el almacenamiento o para buscar algún material cuando era necesario. Allí, no operaba una política de control que monitoreara las condiciones en las que se encontraban los materiales. Cuando se trabaja con el concepto de gestión de colecciones, como se hace desde el 2003 en la reserva patrimonial con la implementación del plan de gestión de colecciones del MdA, no se piensa en un depósito, sino en un lugar donde se llevan a cabo acciones diarias. La transformación de "depósito" a "reserva patrimonial" implica un cambio que refiere al lugar donde se encuentran materiales que devinieron "patrimonio", 8 que es diverso y posee mucha información. El objetivo no solo es conservar la información que tienen, sino también generar nueva información a partir de anexar un archivo, o incorporar prácticas de conservación preventiva cotidiana, como, por ejemplo, registrar diariamente las condiciones de humedad relativa y temperatura o mantener las condiciones óptimas para que no se deterioren las colecciones. Convertido en reserva, el espacio ya no solamente alberga materiales, sino que también dinamiza la información sobre ellos: se da cuenta de identidad, de un periodo histórico, de una forma de vivir en el mundo, se genera un potencial educativo y se articula una política de gestión que

\footnotetext{
${ }^{8}$ Según Prats (1997), el factor determinante que define el patrimonio es "su carácter simbólico, su capacidad para representar simbólicamente una identidad. Esto es lo que explica el cómo y el por qué se movilizan recursos para conservarlo y exponerlo" (Prats, 1997, p. 22). A su vez, este autor, considera que el patrimonio no es un "fenómeno social universal, ya que no se produce en todas las sociedades humanas, ni en todos los períodos históricos; también significa, correlativamente, que es un artificio, ideado por alguien (o en el decurso de algún proceso colectivo), en algún lugar y momento, para unos determinados fines, e implica, finalmente, que es o puede ser históricamente cambiante, de acuerdo con nuevos criterios o intereses que determinen nuevos fines en nuevas circunstancias" (Prats, 1997, p. 20).
}

Anuario de la Escuela de Historia Virtual - Año 11 - No 18 - 2020: pp. 46-68. ISSN: 1853-7049 
incluye a las personas que trabajan con los materiales. Pensar en un proyecto de gestión de colecciones implica, por lo tanto, un plan de trabajo activo, en el cual tiene que haber gente encargada de hacer una conservación preventiva y generar documentación específica sobre los materiales, que los investigue y tome decisiones para preservarlos.

\section{Diagnóstico del estado de conservación de los materiales}

Un primer acercamiento a estos distintos materiales de la colección folklórica me permitió observar que algunos de ellos se encontraban disociados, había documentos que no se correspondían con sus contenedores, muchos de ellos no estaban ordenados cronológicamente o no habían sido inventariados. Así, por ejemplo, debido a su estado de conservación, los discos de pasta no podían ser reproducidos en su formato original, por lo cual, fueron digitalizados en el año 2015. Otros casos encontramos también en algunos materiales que no forman parte de la sección musicología, como los periódicos que recibía el IALF, que no se encontraban en contenedores adecuados, o el corpus de fotografías perteneciente a la colección, que aún se encuentra dividido entre el Archivo de la Reserva y la Sección Americanistas de la Biblioteca de Filosofía y Humanidades y Psicología de la UNC.

La mayoría de los documentos no se encontraban digitalizados; solo había algunos pocos que habían sido tratados de este modo por pedidos especiales, vinculados con la investigación. Por otra parte, la lectura de los informes de investigación me permitió identificar la falta de fichas musicológicas y de discos fonográficos respecto a lo que allí se consignaba, observándose en general un estado irregular de la información en relación con los documentos: algunos carecían de contexto, sin identificación ni siglas sobre los mismos, mientras que otros no estaban ingresados en las fichas de inventario ni en ningún otro soporte de registro documental. A partir de la fragmentación de las colecciones, la carencia de inventarios y la falta del respaldo digital de los documentos del archivo, surgieron estas necesidades de la Reserva Patrimonial y, por consiguiente, la demanda de hacer un trabajo de Conservación Preventiva sobre la producción documental de los trabajos de campo desarrollados por el Instituto de Arqueología, Lingüística y Folklore entre los años 1941 y 1956. Esto permitió contextualizar desde el conocimiento antropológico estos materiales para su puesta en valor y posterior difusión, por medio del repositorio digital Suquía, como parte fundamental de esta práctica profesional supervisada.

\section{¿Cómo asociar un conjunto de objetos dispersos?}

¿De qué nos hablan los objetos de la colección de Musicología? ¿Qué nos pueden decir más allá de su integración en sistemas de clasificación específicos? ¿Qué puede aportar este manojo de objetos, en definitiva, al conocimiento de la relación entre la disciplina del Folklore y la nación?

Anuario de la Escuela de Historia Virtual - Año 11 - N 18 - 2020: pp. 46-68. ISSN: 1853-7049 
52 | La conformación de la colección folklórica del Instituto de Antropología...

El contacto con los objetos a partir de los trabajos técnicos de organización, inventariado, digitalización y carga al repositorio digital Suquía me permitió, como se mencionó anteriormente, adentrarme más en el contenido de las fichas musicológicas y de los discos, lo que me instó a indagar en el propio proceso de conformación de la colección. A través de estas acciones y de la investigación empecé a comprender por qué se habían conservado algunos elementos de las colecciones y por qué otros no, así como los diversos estados de conservación y prácticas orientadas a la conservación y resguardo de objetos. El conocimiento antropológico y el análisis de las relaciones entre los distintos objetos y los documentos, me permitieron, sobre todo, contextualizar los elementos de la colección, el momento histórico de su conformación, las preguntas teóricas en torno a las cuales fueron producidos y las diferentes políticas que intervinieron en su conformación.

No siempre los objetos resguardados en la Reserva del Museo fueron conceptualizados y tratados en función de una lógica patrimonial. Los investigadores que formaron las colecciones tenían incluso su propia concepción respecto a quién pertenecían las colecciones, si a los investigadores o al Estado, y esta aseveración ha permitido entender la posibilidad de que fuesen ellos mismos los responsables de ciertos faltantes en los inventarios (De Carli, 2012, p. 57). A partir del concepto de Biografía cultural de las cosas, explicitado anteriormente, es posible pensar que los objetivos de investigación de cada época, de cada gestión y de las ciencias antropológicas del momento influyeron decididamente sobre: 1) las decisiones de adquisición; 2) la información que se registraba o no al describir los objetos; e incluso 3) su destino. En tanto documento, se le requirió responder a cuestiones de cada momento histórico, sea de la disciplina de base o de temáticas sociales más amplias, cambiantes y hasta contrapuestas (Bonnin, 2007, p. 2).

\section{Período de conformación de la colección musicológica. Criterios y Metodología}

A principios de 1941 se creó el Instituto de Arqueología, Lingüística y Folklore “Dr. Pablo Cabrera", que dependía directamente del Rectorado de la Universidad Nacional de Córdoba. Este Instituto pasaría posteriormente, en 1957, a ser el Instituto de Antropología, dependiente de la Facultad de Filosofía y Humanidades. La disolución de los institutos de esta facultad llevó a que, desde 1987, los mismos pasaran a conformar las áreas del Centro de Investigación de la Facultad de Filosofía y Humanidades $(\mathrm{CIFFyH})$, de la cual quedó afuera el actual Museo de Antropología. Este último, a partir del año 2002, pasó a depender directamente de la FFyH. En el marco de estos cambios institucionales a lo largo del tiempo, los objetos y los documentos con los cuales realicé mi práctica llegaron a la Reserva Patrimonial del Museo de Antropología, con su actual estado de conservación y documentación explicitado anteriormente en el diagnóstico. En el siguiente cuadro destaco algunos hitos importantes en la historia de la colección folklórica de manera cronológica: 


\begin{tabular}{|c|c|}
\hline Evento & Año \\
\hline Creación del IALF & 1941 \\
\hline Inauguración del Museo de Antropología & 1942 \\
\hline Compra del equipo de grabación & 1944 \\
\hline Incorporación oficial de Julio Viggiano Esaín & 1946 \\
\hline $\begin{array}{c}\text { Viggiano Esaín viaja a Buenos Aires a } \\
\text { capacitarse con Carlos Vega }\end{array}$ & 1947 \\
\hline $\begin{array}{l}\text { Suspensión de actividades de Viggiano Esaín } \\
\text { en el IALF }\end{array}$ & 1956 \\
\hline $\begin{array}{l}\text { Cambio de denominación y asunción de Rex } \\
\text { González como director }\end{array}$ & 1957 \\
\hline Instituto de Antropología & 1957 a 1987 \\
\hline $\begin{array}{c}\text { Traslado de Viggiano Esaín al Instituto de } \\
\text { Estudios Americanistas (IAE) }\end{array}$ & 1957 \\
\hline $\begin{array}{c}\text { Publicación del primer tomo del Cancionero } \\
\text { popular de Córdoba en el IAE }\end{array}$ & 1969 \\
\hline $\begin{array}{c}\text { Creación del CIFFyH y disolución de los } \\
\text { Institutos, el MdA queda fuera de este centro } \\
\text { de investigación }\end{array}$ & 1987 \\
\hline Museo de Antropología & Reabre sus puertas al público en 2002 \\
\hline Plan de gestión de colecciones del MdA & Desde el 2003 \\
\hline Repositorio digital Suquía & 2016 \\
\hline Práctica profesional supervisada & $2017-2019$ \\
\hline
\end{tabular}

La colección folklórica comenzó a concretarse como tal a mediados de 1943 durante la gestión de Antonio Serrano como director del IALF, año en que también se incorporó Juan Bialet Tizeira como auxiliar de investigación. En el año 1946 se sumó Guillermo A. Terrera como secretario del Instituto, quien, al año siguiente, fue nombrado adscripto en la rama Folklore con el tema de investigación titulado "Estudio folklórico en la zona de la antigua Ansenuza" (De Carli, 2012, p. 58). Este último aparece como ejecutante en varias de las fichas musicológicas de 1947. También en 1946 se incorporó al IALF como investigador asistente el musicólogo Julio Viggiano Esaín, ${ }^{9}$ quien ya estaba participando de modo no oficial en el Instituto desde hacía más de un año (De Carli, 2012, p. 53). Esta incorporación se dio debido a la necesidad de un especialista para el desarrollo de la sección Musicología. Fue justamente este investigador quien realizó el trabajo más

\footnotetext{
${ }^{9}$ Viggiano Esaín nació en 1899 en Tandil (Buenos Aires). Fue violinista y profesor de dicho instrumento. En Rosario (Santa Fe) llegó a ser violinista solista de la Orquesta del Profesorado orquestal de la provincia. A fines de la década del '30, se instala en la provincia de Córdoba e ingresa a la Orquesta Sinfónica de Córdoba, en donde obtiene el puesto de primer violinista solista. Fue a través de sus aficiones etnomusicológicas que llegó al Folklore, vinculándose al Instituto de Antropología, Lingüística y Folklore en calidad de investigador y encargado de la sección musicología en donde se dedicó a la colección de instrumentos musicales y a la formación del archivo sonoro (De Carli, 2012, p. 53).
}

Anuario de la Escuela de Historia Virtual - Año 11 - No 18 - 2020: pp. 46-68. ISSN: 1853-7049 
54 | La conformación de la colección folklórica del Instituto de Antropología...

prolongado en el área folklórica del Instituto, al menos, hasta el año 1956, cuando fue suspendido debido a conflictos con el director del IALF, Antonio Serrano, en el ambiente de trabajo. En lo que sigue, me voy a centrar en este investigador, debido a que tanto las fichas musicológicas como los discos son producto de sus trabajos en este espacio.

En el año 1947, Bialet pidió una licencia y fue reemplazado por Viggiano Esaín en carácter de Investigador Interino. En 1950, con la renuncia definitiva de Bialet a su puesto, aquél fue confirmado como Ayudante Investigador, cargo que estaba desempeñando de hecho (De Carli, 2012, p. 54). En el marco de su labor de Ayudante Investigador en el IALF, Viggiano Esaín fue adquiriendo progresivamente mayor autonomía y relevancia en su cargo, lo cual impactó en la importancia y crecimiento del Gabinete de Musicología del área de Folklore. Tanto para Antonio Serrano como para los investigadores especialistas en folklore que se incorporaron al Instituto, el "elemento musical tradicional" corría serios riesgos de perder vigencia. ${ }^{10}$ Por un lado, en el contexto del avance de la radio y de los bailes populares modernos, se entendía que estaba destinado a desaparecer. Por otra parte, los medios de comunicación que estaban expandiendo su influencia, habían favorecido un proceso de cambio, misturando los tipos, pobladores y especies, ${ }^{11}$ dando como resultado que, en palabras de Viggiano Esaín, en distintos lugares de la provincia fuera posible encontrar especies de distintas regiones del país. Viggiano consideraba estos cambios folklóricamente como aculturaciones y las atribuía a las corrientes de braceros que viajaban por las distintas zonas agrícolas para la recolección de las cosechas de algodón, de la yerba mate en Misiones y del azúcar en Tucumán, como también a los braceros del sur de la provincia de Córdoba, que se trasladaban a las zonas norteñas para las faenas en los montes, quebrachales, salitrales. Esto justificaba la gran variedad y dispersión o distribución geográfica de las especies, incluso, las de genuino carácter tradicional (Viggiano Esaín, 1969, p. 7). Ello explicaría la variedad de especies como chamamés, bailes indígenas, yaravíes, milongas y estilos reflejada en las fichas musicológicas producto de las recopilaciones.

Este diagnóstico, en el marco de lo que había sido la afluencia de migración europea entre finales del siglo XIX y principios del XX y el contexto general local vinculado al nacionalismo de los años '30 y ‘40, se inscribía en el proyecto intelectual y político propio de la época, que implicaba definir "el verdadero ser nacional" (Lazzari, 2004; Blache y Dupey, 2007; Bonnin, 2007; Díaz, 2009). En este sentido, según ha sido analizado por

\footnotetext{
${ }^{10}$ Esto estaba vinculado al ideal nacionalista de la época, que veía en la modernización y en la inmigración un riesgo para la identidad nacional.

${ }^{11}$ Carlos Vega, referente teórico y metodológico de Viggiano Esaín, expone en su libro "Panorama de la música popular argentina", de 1944, que las personas normalmente, al escuchar música, no oyen sistemas tonales, rítmicos o armónicos, ni cancioneros. Lo que se escucha son "piezas" de una especie más o menos determinada. Estas piezas, en gran medida, presentan una forma o formas particulares que el "pueblo" normalmente distingue, y que constituyen la única manifestación práctica de los cancioneros. Una especie, según este punto de vista, puede abarcar formas diversas y adoptar músicas de distintos cancioneros, y a pesar de su vaguedad, la especie adopta, en la clasificación para las subdivisiones de los cancioneros, el nombre popular con que se ha recopilado en el campo y que está fuertemente vinculada al aspecto rítmico (como la chacarera, la zamba, el gato, etc.).
}

Anuario de la Escuela de Historia Virtual - Año 11 - N 18 - 2020: pp. 46-68. ISSN: 1853-7049 
estos autores, los investigadores de la época se concebían a sí mismos como agentes cuya misión era rescatar determinadas "expresiones folklóricas" con el objeto de describirlas, clasificarlas y preservarlas. En este marco, según se desprende del trabajo de Bonnin (2007, p. 69), en el año 1944 la Universidad Nacional de Córdoba compró un costoso equipo de grabación portátil -que aún se encuentra en la Reserva del Museo de Antropología, el segundo existente en el país-12 y fue utilizado por los investigadores en sus registros de la "música tradicional" de las sierras de Córdoba, al menos, hasta el año 1956. Esto dio lugar a la vasta colección de registros musicales en discos de pasta y partituras que forman parte de la colección del Museo con los cuales trabajé.

En la investigación realizada pude constatar que las políticas de investigación y difusión del folklore habían empezado a ser favorecidas desde la década de 1930. Claudio Díaz, en "Variaciones sobre el ser nacional" (2009), realizó una breve contextualización sobre el Folklore en aquella década, en el marco nacional de industrialización y migraciones internas hacia los grandes centros urbanos. En su análisis, Díaz muestra cómo, junto con las personas, llegaron a las ciudades géneros musicales provenientes de las áreas rurales del país, que empezaron a ser reproducidos por la radio -novedoso dispositivo de comunicación en aquel momento- y requeridos por la industria discográfica, pasando así de ser un conjunto de géneros tradicionales de carácter más bien comunitario, a constituirse en músicas populares de carácter masivo (Díaz, 2009, p. 31). En este marco, varios investigadores coinciden en afirmar que la condición básica para la constitución de un mercado para el folklore fue el fenómeno de las migraciones internas que acompañó el proceso de industrialización que se desarrolló en los años 30 y se acentuó con la Segunda Guerra Mundial. ${ }^{13}$ De este modo, tanto los conservadores del gobierno de la Concordancia (1932-1943), como los militares nacionalistas $\mathrm{y}$, posteriormente, el gobierno peronista, adoptaron políticas que impulsaron el estudio y la difusión del folklore a nivel nacional (Chamosa, 2012, p. 17).

En este marco, en el Informe anual del año $1945,{ }^{14}$ el director del IALF planteaba que el aumento del material folklórico exigía la instalación de una sala especial para albergar el material y que, de hecho, haría falta habilitar otras más. Así, se creó el Gabinete de Musicología, como un centro de investigaciones y estudios de la música indígena y criolla en todos sus aspectos, y se dio a la misma el significado de una "contribución a las Ciencias del Hombre o Antropológicas" (Viggiano Esaín, 1948, nota preliminar). Esta sección de Musicología estaba compuesta por archivos fonográficos, fotográficos, periodísticos, cartográficos, ficheros musicológicos, historias, musicoteca y bibliografía de la materia, entre otros objetos.

${ }^{12}$ El primero fue adquirido por Carlos Vega.

${ }^{13}$ La necesidad de mano de obra para la industria generó un traslado masivo de provincianos de todas las latitudes a las grandes ciudades como Córdoba, Rosario y mayoritariamente a Buenos Aires. Esto cambió la fisonomía de las ciudades dando lugar a una nueva urbanización, con un aumento acelerado de la población y el crecimiento de las zonas aledañas, como el Gran Buenos Aires (Blache, 1992; Díaz, 2009, p. 64; Chamosa 2012).

${ }^{14}$ AMdA, Colección documental Serrano.

Anuario de la Escuela de Historia Virtual - Año 11 - No 18 - 2020: pp. 46-68. ISSN: 1853-7049 
56 | La conformación de la colección folklórica del Instituto de Antropología...

A partir de la documentación del IALF, que se encuentra en la Reserva, fue posible reconstruir en parte el modo en que se fue conformando la sección Musicología. Pude constatar en una carta dirigida al Rector de la Universidad, ${ }^{15}$ que, en 1942, Antonio Serrano estaba ultimando los trabajos necesarios para la apertura oficial del IALF prevista para la segunda quincena de octubre de ese año. En esta carta, Serrano plantea que era necesario un especialista que se dedicase a la labor folklórica de manera constante y que, en ese sentido, realizase tareas de recolección de cantares, tradiciones y música, entre otras cosas, con el objetivo de preparar el Cancionero Popular de Córdoba. ${ }^{16}$ A su vez, recomendaba para esa tarea a Juan Bialet, que, en ese momento, se desempeñaba como auxiliar de tesorería en el instituto, por su interés en el folklore y sus métodos de investigación.

El 16 de septiembre de 1942 Serrano envía otra carta al Rector de la Universidad para informarle de que, en la inauguración del Museo de Antropología de la Universidad, en donde se expondrían las colecciones del IALF, el musicólogo Carlos Vega daría una disertación sobre "La Música Popular de Córdoba". ${ }^{17}$ Serrano aspiraba a que el Museo estuviera abierto al público durante algunos días a la semana, sirviendo así a "la cultura popular". Carlos Vega, creador, organizador y sistematizador de la ciencia musicológica en Argentina, autor de un método para la materia particularmente aplicado al canto popular y de una obra de investigación musicológica en el ambiente americano, realizó en el marco de este viaje a Córdoba una gira con su equipo fono-eléctrico para recolectar canciones en el oeste provincial. En el Museo de Ciencias Naturales "Bernardino Rivadavia" de Buenos Aires, Vega organizó y dirigió el Instituto de Musicología (que luego devino en el Instituto Nacional de Musicología), y también desempeñó desde 1933 el cargo de técnico de Folklore en el Instituto de Literatura Argentina, que dirigió Ricardo Rojas, ${ }^{18}$ en la Facultad de Filosofía y Letras de Buenos Aires (Viggiano Esaín, 1948 , p. 8) $\cdot{ }^{19}$ Es posible observar aquí un vínculo entre el Folklore, como disciplina, y el Museo como centro de investigación y de difusión, y también entre el Folklore y la

${ }^{15}$ AMdA, Correspondencia emitida al Rectorado 41-45.

${ }^{16}$ Hasta ese momento, Juan Alfonzo Carrizo había publicado los Cancioneros Populares de Catamarca (1926), Salta (1933), Jujuy (1934), Tucumán (1937) y el de La Rioja (1942). Por su parte, Orestes Di Lullo publicó el Cancionero de Santiago del Estero (1940), con prólogo y notas de Carrizo (Blache y Dupey, 2007, p. 314).

${ }^{17}$ AMdA, Colección documental Serrano.

${ }^{18}$ Rojas (San Miguel de Tucumán, 16 de septiembre de 1882 - Buenos Aires, 29 de julio de 1957) fue un poeta, dramaturgo, orador, político e historiador argentino.

${ }^{19}$ Carlos Vega ingresó en 1926 al Museo de Ciencias Naturales "Bernardino Rivadavia”. En 1931, en dicha institución se creó el "Gabinete de Musicología Indígena", que, en 1944, pasó a denominarse "Instituto de Musicología". En 1948, por decreto presidencial, dicho instituto se separó del Museo y fue dirigido por su fundador (Carlos Vega). Desde 1971, se denominó Instituto Nacional de Musicología y, en 1973, se determinó su nombre actual (https://inmcv.cultura.gob.ar/info/el-instituto/). Actualmente, el Instituto cuenta con un gran archivo sonoro, fonográfico, fotográfico, de instrumentos musicales aborígenes y criollos, manuscritos y partituras de música argentina. Cuenta también con una fonoteca y una biblioteca especializada en música argentina y latinoamericana, que se encuentra abierta al público (https://www.cultura.gob.ar/institucional/organismos/museos/instituto-nacional-de-musicologia-carlosvega/).

Anuario de la Escuela de Historia Virtual - Año 11 - No 18 - 2020: pp. 46-68. ISSN: 1853-7049 
Universidad. Hay una similitud con el caso de Córdoba, solo que allí el Museo dependía directamente de la Universidad.

Vega enseñaría su manejo y técnica del grabador fono-eléctrico a Juan Bialet, quien las aplicó en el equipo similar que el Instituto adquiriría un par de años después para "poder realizar las investigaciones folklóricas de forma completa y con métodos modernos". Pero antes, el 1 de octubre de 1942, ${ }^{20}$ Serrano envía al Secretario General de la Universidad una carta adjuntando una factura por la compra de una máquina fotográfica Contax y accesorios adquiridos por el instituto. Otro documento que permite reconstruir la constitución de la sección de Musicología es una carta emitida por Serrano al interventor de la Universidad, ${ }^{21}$ el 20 de marzo de 1944.22 Allí, plantea que la sección se estaba organizando con el propósito de conservar en discos "toda la música popular de Córdoba" y, también, de provincias vecinas. En esta carta, Serrano le informa al interventor que Juan Bialet había sido entrenado por el musicólogo Carlos Vega en un viaje de aprendizaje y que ya estaba en condiciones de realizar él mismo las recolecciones. Al mismo tiempo, sigue en la búsqueda de formar un musicólogo bajo la dirección técnica del mismo Vega. Finalmente, destaca la necesidad de adquirir un equipo grabador portátil, de 220 volts, corriente alternada 105 w., 60 ciclos. 4 válvulas 1- 6F6- 2- 6J7- 1- 5x46. Con micrófono dinámico RCA Victor o equivalente, Pick-up reproductor y grabador por separado, instrumento indicador de nivel de grabación, control de tono, parlante para reproducción y enchufe para teléfonos de control (auriculares). Serrano consideraba importante "que sea un aparato de marca".

En el año 2014, se realizó una muestra sobre "los folkloristas" en el Museo de Antropología, en donde este aparato de grabación estuvo en exposición. No fue fácil dar con él, en la Reserva me decían que el objeto había quedado en el Museo, mientras que en el Museo me decían que había vuelto a la Reserva. Poco antes de terminar mi práctica, uno de los técnicos me sugirió que me fijase en el Archivo de la Reserva, en una caja que estaba detrás de la máquina de escribir que -supuestamente- había pertenecido a Antonio Serrano. Efectivamente, allí, junto con una partitura y un disco que habían sido usados para la muestra, encontré la grabadora portátil que había sido utilizada por los investigadores del IALF para registrar la música y las historias orales en sus viajes de campo.

\footnotetext{
${ }^{20}$ AMdA, Colección documental Serrano.

${ }^{21}$ La Universidad fue intervenida en distintos momentos, debido a la política intervencionista de grupos de las Fuerzas Armadas, entre los años 1943, 1945 y 1946 (De Carli, 2012, p. 46).

${ }^{22}$ AMdA, Colección documental Serrano.
}

Anuario de la Escuela de Historia Virtual - Año 11 - Nº 18 - 2020: pp. 46-68. ISSN: 1853-7049 
58 | La conformación de la colección folklórica del Instituto de Antropología...

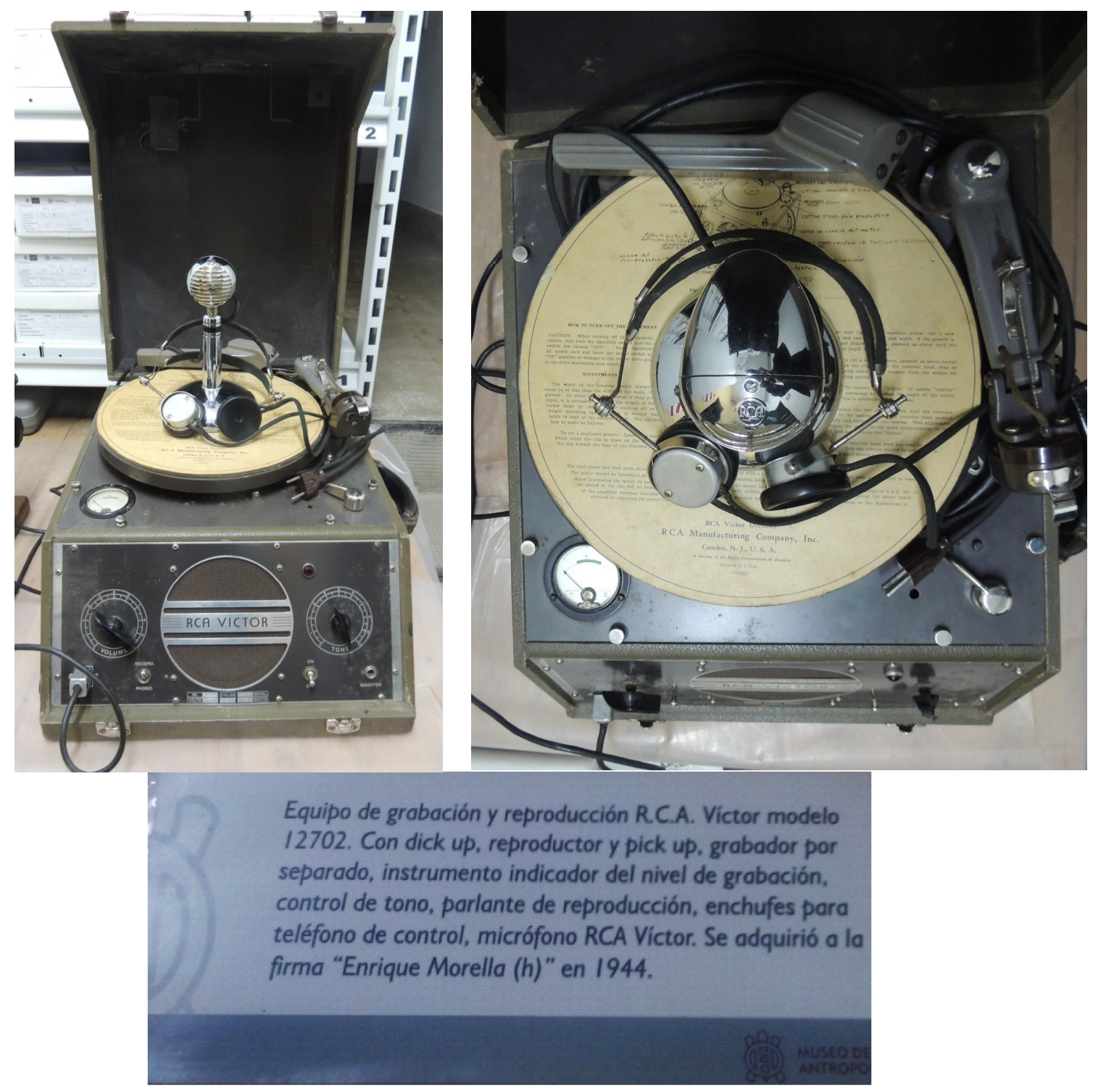

Mediante una búsqueda en internet pude obtener un fragmento de un manual de usuarios de este tipo de grabadoras, que estaba en inglés y que describía las siguientes características del aparato:

ML12702 es una grabadora de discos instantáneos de tipo portátil que consiste en una mesa giratoria, un cabezal de corte, un cabezal de recogida (pick-up), un amplificador de 3 vatios, un altavoz dinámico y un micrófono tipo MI-6228. La velocidad del plato giratorio es de 78 r.p.m. y el plato giratorio se adaptará a discos de cualquier diámetro de seis a doce pulgadas (entre 15,24 y 30,48 cm). Se recomienda que se utilicen los discos de grabación instantánea RCA para grabar con este equipo. El equipo también se puede utilizar para reproducir discos estándar de $78 \mathrm{rpm}$, se recomiendan para este uso las púas de cromo RCA Victor Green. Este instrumento grabará y reproducirá instantáneamente discos del tipo de disco de aluminio revestido de laca. Se puede usar una púa de corte de acero o de zafiro. La púa de acero es satisfactoria para aproximadamente 15 minutos de grabación real, después de lo cual debe desecharse, mientras que el zafiro puede usarse durante

Anuario de la Escuela de Historia Virtual - Año 11 - No 18 - 2020: pp. 46-68. ISSN: 1853-7049 
aproximadamente 12 horas de grabación y luego puede devolverse a la fábrica para volver a afilar. Los registros realizados con una púa de zafiro tienden a tener menos ruido en la superficie que los registros hechos con una herramienta de acero, sin embargo, el ruido de la superficie es muy bajo en los registros realizados con cualquier tipo de púa. ${ }^{23}$

Las características técnicas de este aparato reflejan las necesidades del trabajo de los folkloristas de reproducir los discos de recopilaciones grabados previamente para poder transcribir los audios en las fichas musicológicas y posteriormente realizar un análisis de las partituras.

Es importante destacar que la zona elegida para iniciar estas colecciones fue el noroeste de la provincia de Córdoba, el departamento Cruz del Eje y sus zonas aledañas, con la intención de ampliar las investigaciones a otras regiones provinciales y nacionales (Bonnin, 2007, p. 68). Esta zona estaba más ligada a la música y las tradiciones del noroeste argentino y representaba en los imaginarios académicos una región de resguardo de tradiciones que aún se encontraban en un estado de relativa "pureza".

En este sentido, en el año 1969, Viggiano Esaín publica el primer tomo del Cancionero popular de Córdoba en el Instituto de Estudios Americanistas (IAE) perteneciente a la FFyH. ${ }^{24}$ A partir del prólogo del Cancionero, podemos saber que, por su posición geográfica dentro del país, la provincia de Córdoba presentaba para los folkloristas la particularidad de ser una zona de confluencia de "las más diversas corrientes culturales". Viggiano Esaín consideraba que la zona central y todo el noroeste de la provincia de Córdoba se encontraba "enmarcado en el cuadro de su pintoresca serranía" y atesoraba las riquezas de su tradicionalismo típico, todavía fuertemente acaudalado por los valores culturales y sociales de la vieja usanza española, característicos de la formulación cultural de nuestro país (Argentina) desde los siglos de la colonización hasta el final del siglo XIX (Viggiano Esaín, 1969, p. 4). Según el folklorista, esa característica se veía reflejada en "acentuado grado de pureza" en los lugares serranos más apartados de las vías de comunicación, y relativamente, en los que impactaba la influencia de las corrientes turísticas. Los investigadores del IALF hacían viajes a estas regiones. El objetivo principal de estos viajes era la preparación de un trabajo en conjunto sobre las costumbres, la cultura material y la música de los pobladores de las sierras cordobesas, a quienes denominaban "criollos". Estos eran vistos como portadores vivos de las tradiciones que estaban en proceso irremediable de desaparición debido al avance de la modernidad en las ciudades del interior y en las zonas rurales, y a los cambios generados por el ingreso masivo de inmigrantes europeos en el país (Bonnin, 2007, p. 68). Y, en este sentido, para Antonio Serrano, la tarea del gabinete de Musicología consistía en salvaguardar para el futuro el acervo musical de Córdoba que, hacia 1944, ya había sido sustituido en gran parte, según el arqueólogo, "por el suministro por

${ }^{23}$ Nombre: Models MI-12701, MI-12702 portable disc recording equipment installation instructions and service data URL: https://i.ebayimg.com/images/g/7nEAAOSwpDdVQBSG/s-1400.jpg (Consultado: 27/03/2019). La traducción es de mi autoría.

${ }^{24}$ Viggiano Esaín había sido trasladado al IAE en 1957 debido a los conflictos mencionados anteriormente.

Anuario de la Escuela de Historia Virtual - Año 11 - No 18 - 2020: pp. 46-68. ISSN: 1853-7049 
60 | La conformación de la colección folklórica del Instituto de Antropología...

corrientes extranjerizantes a través de radios y fonográfico" (citado en: De Carli, 2012, p. $62)$.

En un documento sin fecha que se encontraba en el mismo contenedor que las fichas musicológicas pude conocer el "Plan u objeto fundamental de la Sección Musicología", que se proponía:

El estudio de la música, danzas e instrumentos de los primitivos habitantes de América, y de los grupos mestizos y criollos en sus aspectos arqueológicos, etnográficos y folklóricos; El estudio de la música, danzas e instrumentos de carácter popular; Colectar música indígena y popular de Argentina y de América, obtenida mediante el procedimiento de grabación fono-eléctrica y por el de la notación directa; Colectar coreografía indígena y popular representativa, clasificados dentro de sus áreas de dispersión o zonas geográficas, caracteres morfológicos, génesis, etc.; Colectar instrumentos indígenas y folklóricos representativos; Generar un archivo fonográfico de todas las especies de música, danzas, sonidos de instrumentos, textos poéticos de canciones y bailes, indígenas y populares, obtenidas por el procedimiento de la grabación; Generar un archivo fotográfico con las fotografías del músico en su medio y detalles técnicamente importantes: posición del instrumento, de las manos, del ejecutante, maneras, actitudes, gestos, etc. y de las escenas de danzas: evoluciones coreográficas, esquemas figurativos, aspectos mimográficos, maneras, actitudes, tipos; Generar un archivo documental de los antecedentes y referencias biográficas de los ejecutantes y de las especies musicales e instrumentos indígenas y folklóricos de las especies musicales, coreográficas, mimográficas y poéticas obtenidas por el procedimiento de la notación directa; Describir los detalles técnicamente importantes: evoluciones coreográficas, esquemas figurativos, aspectos mimográficos, maneras, actitudes y tipos. Recopilar respuestas a cuestionarios sobre especies antiguas desaparecidas, en vías de extinción o en vigencia, y de toda referencia aclaratoria de los procesos evolutivos de las especies musicológicas; Criterio extensivo: "Viajes de estudio a los lugares más interesantes". ${ }^{25}$

En el Cancionero Popular de Córdoba, Viggiano describe algunos de los intereses de sus viajes de recolección. En lo que respecta al campo de las creencias, "las ideas cosmogónicas sustentadoras del espíritu popular" eran interpretadas como series de supersticiones de una gran variedad, entre ellas la "magia popular, seres, elementos y prácticas mágicas, positivas y negativas; sucesos mágicos, animismo popular; cultos, creencias y usos supersticiosos", la demonología, las prácticas medicinales de carácter empírico, mágico o mixto, que observaba en Córdoba y destacaba en su extraordinaria vitalidad en los ambientes estudiados (Viggiano Esaín, 1969, p. 11). ${ }^{26}$

A partir del texto de Viggiano Esaín de 1948 Escuela musicológica argentina es posible reconstruir la organización y la metodología de trabajo que utilizaban los folkloristas del Instituto. En base a mi trabajo con los documentos durante la práctica profesional

25 "Plan u objeto fundamental de la Sección Musicología", Archivo del Museo de Antropología (AMdA), Colección Folklórica, Caja "Fichas musicológicas".

${ }^{26}$ Otro aspecto indicado por su autor, el de la sociabilidad criolla, se encontraba representado en una variedad de juegos, pasatiempos, costumbres, modalidades típicas de la vida de relación, fiestas familiares y sociales y en la cocina popular integrada por las comidas, dulces y bebidas regionales tradicionales (Viggiano Esaín, 1969, p. 12).

Anuario de la Escuela de Historia Virtual - Año 11 - N 18 - 2020: pp. 46-68. ISSN: 1853-7049 
supervisada, específicamente con la caja de "Investigaciones folklóricas", ${ }^{27}$ fue posible constatar que dicha publicación surge de un informe que le envía el mismo Viggiano Esaín a Antonio Serrano el 11 de abril de 1947, en torno a la metodología de trabajo aprendida de Carlos Vega durante un viaje de capacitación a Buenos Aires en el Gabinete Musicológico del Museo de Ciencias Naturales "Bernardino Rivadavia". Dicho texto me permitió comparar las prácticas propuestas en el libro con los registros documentales conservados en la Reserva Patrimonial.

\section{Folklore y nacionalismo en el Gabinete de Musicología del IALF}

El Gabinete de Musicología del IALF siguió los principios y los métodos de la Escuela Musicológica Argentina fundada por Carlos Vega. Dicho gabinete fue, en palabras de Viggiano Esaín, el primero de este carácter en el interior del país (Viggiano Esaín, 1948, nota preliminar). En la nota preliminar del libro, Viggiano agradece a Antonio Serrano, director del IALF al momento de la publicación, por su colaboración en la estructuración y organización del gabinete, mientras que también le agradece por el "estímulo moral y la comprensión cabal" del problema que constituía la disciplina del folklore, su "posición y proyección final en el panorama de las investigaciones antropológicas y la significación patriótica de la misma, dentro del cuadro de la ciencia genuinamente argentina". Carlos Vega consideraba a la Musicología como una ciencia organizada que en Argentina ofrecía un “cuerpo orgánico de doctrina y de materia y una obra con sólida fundamentación científica, y que resume en su intimidad esencial, el carácter, fisonomía y espíritu del genuino sentimiento de la nacionalidad" (Viggiano Esaín, 1948, p. 5). La Escuela de Musicología Argentina, fundada, como se dijo anteriormente, por Vega, buscaba aportar en el terreno de la música popular, folklórica, que constituía "el basamento inconmovible de la fisonomía espiritual, la raíz tradicional, y la fuerza telúrica que alimenta el sentimiento racial de un pueblo" (Viggiano Esaín, 1948, p. 5). Viggiano opinaba que la musicología argentina era pionera en el mundo. Los seguidores de esta corriente consideraban el canto popular, anónimo, sus músicas, sus bailes, sus instrumentos y los problemas de orden músico-etnográfico y folklóricos como expresivos de las manifestaciones anímicas del pueblo, que, para ellos, representaban "el hilo interminable de la tradición que une el remoto pasado con el presente, palpitante y vivaz" (Viggiano Esaín, 1948, pp. 5-6). En ese momento, los folkloristas buscaban posicionar a la musicología argentina como una ciencia genuina a partir de sus conclusiones teóricas y sus principios metodológicos que se aplicaban de forma práctica en el campo de la investigación experimental. Se produjo un cuerpo de doctrina y una gran cantidad de motivos musicales recogidos en el trabajo de campo.

Como se mencionó anteriormente, los folkloristas y sus prácticas estaban estrechamente vinculados con el desarrollo del nacionalismo, que, a su vez, se

\footnotetext{
${ }^{27}$ Archivo del Museo de Antropología (AMdA), Colección Folklórica, Caja "Investigaciones folklóricas".
} 
62 | La conformación de la colección folklórica del Instituto de Antropología...

enmarcaban en un contexto nacionalista más amplio. El concepto de la nación como una "comunidad imaginada", planteado por Benedict Anderson (1993 [1983]), ayuda a comprender las raíces culturales del nacionalismo y las consecuencias que traía el mismo para la cohesión social de una nación. Este autor propuso que la nacionalidad es el valor más universalmente legítimo en la vida del siglo XX; que la nacionalidad, o la "calidad de nación", al igual que el nacionalismo, son artefactos culturales de una clase particular, con una legitimidad emocional muy profunda. El autor define a la nación como una comunidad política imaginada, inherentemente limitada y soberana. Se imagina como comunidad porque, independientemente de la desigualdad y la explotación que se da en la nación, esta se concibe siempre como un compañerismo profundo y horizontal; limitada, porque incluso la mayor de ellas tiene fronteras finitas, más allá de las cuales se encuentran otras naciones; y se imagina soberana, porque el concepto nació en una época en la que la Ilustración y la Revolución estaban destruyendo la legitimidad del reino dinástico jerárquico, divinamente ordenado. Las naciones sueñan con ser libres, la garantía y el emblema de esta libertad es el Estado soberano. ${ }^{28}$ La importancia de este concepto en el caso de los folkloristas radica en que los mismos, a partir de sus recopilaciones y publicaciones, buscaban generar los fundamentos de una comunidad imaginada argentina dentro de la cual la comunidad imaginada cordobesa era una parte constitutiva de esa argentinidad. Sus investigaciones tenían como objetivo apoyar la creación de una identidad nacional atribuyéndole una procedencia auténtica y tradicional desde tiempos antiguos. Esto se puede ver en lo propuesto por Viggiano Esaín en el Cancionero Popular de Córdoba, cuando postula que "el Folklore es una ciencia de amor, debido a que une a todas las clases sociales dentro de cada país" (Viggiano Esaín, 1969, p. 14). Para él, la identidad sustancial que subyace a todas las manifestaciones del Folklore, más allá de las variaciones regionales que tipifican lo folklórico, hace que la ciencia del Folklore opere como una fuerza que une en la sociedad. A su vez, Viggiano sostenía que existiría un Folklore universal que uniría a todos los países del mundo. Dentro de este contexto nacionalista más amplio, para Carlos Vega, era posible reconocer distintas tradiciones dentro de un mismo país, pero destacaba que los tradicionalistas debían ser fervorosos "ciudadanos de la Nación” y unificar el país en su corazón. Así, ellos podrían sentir todas las tradiciones argentinas como suyas, vivas y activas, aunque nunca las hayan reproducido sus antepasados, aunque jamás las hubieran visto o sentido en su medio original, aunque hayan sido hijos de extranjeros o fueran extranjeros ellos mismos (Vega en Díaz, 2009, p. 64). Además, Vega fue un

\footnotetext{
${ }^{28}$ Este autor plantea tres paradojas: en primer lugar, la modernidad objetiva de las naciones a la vista del historiador, frente a su antigüedad subjetiva a la vista de los nacionalistas. Por otra parte, la universalidad formal de la nacionalidad como un concepto sociocultural. En el mundo moderno, todos tienen y deben "tener" una nacionalidad, frente a la particularidad irremediable de sus manifestaciones concretas, específicas. Finalmente, el poder "político" de los nacionalismos, frente a su pobreza y aún incoherencia filosófica. Anderson sostiene que todas las comunidades mayores a las aldeas primordiales de contacto directo (y quizás incluso estas también) son imaginadas y que las comunidades no deben distinguirse por su falsedad o legitimidad, sino por el estilo con el que son imaginadas.
}

Anuario de la Escuela de Historia Virtual - Año 11 - N 18 - 2020: pp. 46-68. ISSN: 1853-7049 
folklorista que impulsó una teoría propia de la ciencia del Folklore. Según esta escuela de estudios, el fundamento ideológico o teoría esencial del Folklore eran las supervivencias, entendidas como hechos folklóricos eliminados de los grupos sociales superiores (lo que refiere a lo "moderno"), que aún mantienen vigencia en los grupos sociales inferiores (que refiere a lo "antiguo"), no adjudicándoles mayor o menor calidad, sino entendiéndolos como partes en un simple proceso dinámico, de tránsito material de lo de arriba a lo de abajo. La supervivencia era un hecho antiguo y actual, cargado de sentido debido a que se hablaba de tiempos pasados y, por eso, era capaz de alimentar una ciencia histórica como el Folklore: “Su lugar predominante era la campaña -el pueblo, la aldea, la habitación aislada- adoptadora y adaptadora tardía de los bienes superiores, o asiento de patrimonios relegados en masa" (Vega, 1944, p. 28). Según Vega, debido a que estos bienes culturales prolongaban su existencia en la campaña, el Folklore incorporaría a la historia a "todo un gran sector humano desconocido, olvidado, menospreciado, parte de la nación, brazo de su prosperidad económica y, en las épocas de desvío, depositario de valiosas reservas morales y hasta de formas y estilos artísticos" (Vega, 1944, p. 29). Martha Blache (1992), en ese sentido, explica que "las corrientes nacionalistas entendían lo folklórico como una cultura marginal, que en su paso de las capas 'superiores' a las 'inferiores' sufría deterioro y arrinconamiento, o que al traspasar de los sectores hegemónicos a los subalternos daba lugar a una apropiación desigual" (Blache, 1992, p. 84).

Viggiano Esaín tomó como modelo a seguir el Instituto de Musicología del Bernardino Rivadavia y se propuso replicar la experiencia en el IALF a través de las recopilaciones. El Gabinete y el Museo del Instituto de Musicología en Buenos Aires poseía, en 1947, 6.000 especies musicales grabadas o anotadas al dictado, fichadas y catalogadas, con sus respectivos textos literarios, expresiones coreográficas y un estudio musicológico de las especies recogidas en su ambiente originario, que correspondían a los diferentes matices del cancionero musical argentino. Contaba dentro de su acervo, en ese momento, con archivos, índices y ficheros organizados con sus respectivos sistemas clasificatorios y estaba dotado de los instrumentos necesarios para las grabaciones, reproducciones, etc. Poseía también una sala de exhibiciones o museo con unos doscientos ejemplares de instrumentos musicales, indígenas y criollos representativos de las diversas culturas y zonas americanas. Tenía una biblioteca con el material bibliográfico básico de la especialidad y contaba también con numerosos gráficos, exposiciones cartográfica y fotográfica y las publicaciones técnicas (obras musicales, musicológicas, etc.) realizadas por el personal técnico del museo (Viggiano Esaín, 1948, p. 9). La musicalidad vernácula, que era recogida de fuentes originarias y cuyos fundamentos étnicos eran estudiados por la Escuela de Carlos Vega, no era únicamente la expresión psicológica, la restauración o el descubrimiento del "alma argentina" contenida en los giros y motivos de sus danzas y canciones, sino también el "verdadero y último fin de todo este movimiento espiritualmente estético nacionalista, la creación de grandes formas musicales adecuadas a nuestra íntima modalidad de ser y 
64 | La conformación de la colección folklórica del Instituto de Antropología...

a la naturaleza esencial del pensamiento y sentimiento musical argentino, con proyección universalista" (Viggiano Esaín, 1948, p. 12).

Esta estética era, para Viggiano Esaín, el resultado de una "íntima modalidad del espíritu argentino", que se inscribía dentro de la universalidad que integraba el conglomerado humano, y consideraba esto como la estructuración del genuino espíritu nacionalista proclamado por Ricardo Rojas (Viggiano Esaín, 1948, p. 12).

En esta dirección, otro concepto que sirve para entender mejor el afán de los folkloristas por recopilar los registros de las costumbres de lugares alejados de las principales ciudades y con poblaciones principalmente campesinas, es el de la "Invención de la tradición", que propuso Eric Hobsbawm en 1983. Las tradiciones inventadas son una herramienta que tiene el nacionalismo para consolidarse a través de la recopilación de costumbres aparentemente antiguas. Hobsbawm (2002 [1983]) plantea que las "tradiciones" que parecen o reclaman ser antiguas son a menudo bastante recientes en su origen $y$, a veces, inventadas. La "tradición inventada" implica un grupo de prácticas, normalmente gobernadas por reglas aceptadas abierta o tácitamente y de naturaleza simbólica o ritual, que buscan inculcar determinados valores o normas de comportamiento por medio de su repetición, lo cual implica automáticamente continuidad con el pasado. Así, puede haberse aplicado la recopilación por parte de los folkloristas. En resumen, hay respuestas a nuevas situaciones que toman la forma de referencia a viejas situaciones, o bien, que imponen su propio pasado por medio de una repetición casi obligatoria. Es interesante el uso de antiguos materiales para construir tradiciones inventadas de género nuevo para propósitos nuevos. Una gran reserva de estos materiales se acumula en el pasado de cualquier sociedad, y siempre se dispone de un elaborado lenguaje de práctica y comunicación simbólicas. Tal interrupción se hace visible incluso en los movimientos que se describen deliberadamente a sí mismos como "tradicionalistas" y que apelan a grupos que, por sentido común, están considerados como los depositarios de la continuidad histórica y la tradición, tales como los campesinos. De hecho, la aparición de movimientos para la defensa de las tradiciones, ya sean "tradicionalistas" o de otro tipo, es una indicación de esta interrupción. En el caso de los folkloristas en Córdoba, la interrupción era planteada en relación con los nuevos medios de transporte, como los trenes, los automóviles y los aviones; a los nuevos medios de comunicación en los '40, como la radio; y a la industrialización de las grandes ciudades, que atraían a grandes masas de gente rural. Estos contactos, para los folkloristas, estaban acabando con la forma de vida tradicional argentina. Estas tradiciones inventadas parecen pertenecer a un tipo que establece o simboliza cohesión social o pertenencia al grupo, ya sea, de comunidades reales o artificiales. Se puede sugerir provisionalmente que este tipo es el dominante, y que las otras funciones se consideran implícitas o surgidas de un sentido de identificación con una "comunidad" y/o las instituciones que la representaban, expresaban o simbolizaban como "nación". Es posible así entender las tradiciones inventadas como una herramienta que tiene el 
nacionalismo a la hora de generar una comunidad imaginada, en el sentido que plantea Anderson (1993 [1983]), citado anteriormente.

En esta línea, la propuesta de Viggiano Esaín en su labor de folklorista consistía en:

mirarnos a nosotros mismos, nuestro propio interior; colocarnos en una especie de posición de introversión para descubrir los perfiles de nuestra genuina fisonomía espiritual; para captarla objetivándola en el arte como suprema expresión del sentimiento del alma nacional. Debemos encaminarnos a sus fuentes, y, para ello, debemos también conocer el camino seguro que nos lleve a su posesión. La escuela musicológica argentina nos enseña el camino y nos exhibe un inmenso tesoro de sus fuentes vírgenes (...) Así cantaremos en nuestro arte lo que es nuestro, lo que sentimos de veras por ser pedazo de nosotros mismos, y al cantar lo nuestro también cantaremos lo universal; desde nuestro lugar, desde este rincón de la tierra argentina hacemos universalismo, ya que nosotros integramos el conglomerado humano y lo definimos con los rasgos espirituales inconfundibles que caracterizan nuestra personalidad de pueblo (Viggiano Esaín, 1948, p. 12).

Este último fragmento de puño y letra de Viggiano Esaín se relaciona directamente con la "comunidad imaginada", por la forma de escribir en un nosotros inclusivo, extensivo a todos los miembros de la nación, y con la "invención de la tradición", por la referencia que hace al pasado al que hay que volver. La ingeniería social que menciona Hobsbawm (2002 [1983]) se puede observar en que el texto tiene como objetivo despertar el nacionalismo en los lectores y encuentra en el folklore un medio propicio para transmitir ese sentimiento.

Es importante aclarar que luego del periodo desarrollado aquí, a partir de 1957 cuando el IALF pasa de ser dirigido por Antonio Serrano a serlo por Alberto Rex González, a la vez que cambia su denominación por Instituto de Antropología (IA), comienza una nueva etapa. Entre 1959 y 1960, se trasladó gran parte de las colecciones folklóricas, aunque algunas quedaron en el Instituto de Antropología, que, en ese momento, funcionaba en la calle Obispo Trejo.

A través de entrevistas realizadas a antiguos no docentes que ya no trabajan en la Facultad (algunos se jubilaron y otros murieron), Mirta Bonnin se enteró de que, en el traslado de la colección, los objetos fueron depositados en el subsuelo del Pabellón España de la ciudad universitaria. Entre ellos, había instrumentos musicales de la colección e, inclusive, elementos de grandes dimensiones como los telares etnográficos que los folkloristas habían comprado por su interés en los oficios criollos. ${ }^{29}$ Este traspaso no se realizó de una manera organizada y tampoco se han encontrado documentos del traspaso formal de la colección de un instituto al otro. Es probable que los objetos y documentos que quedaron en el IA hayan quedado allí porque nadie se acordó de sacarlos. Lo que se mantuvo, además, fue una mínima parte, si se compara con los informes de los años en que ingresaban cientos de piezas a esta colección. El contexto de la época del traslado fue de muchos cambios, muchos movimientos, una etapa bastante

${ }^{29}$ Desde ese momento, quedaron en la Reserva Patrimonial fichas de los objetos.

Anuario de la Escuela de Historia Virtual - Año 11 - N 18 - 2020: pp. 46-68. ISSN: 1853-7049 
66 | La conformación de la colección folklórica del Instituto de Antropología...

convulsionada para el IA, que fue luego afectado por la dictadura entre 1966 y 1973, la intervención de la Universidad en 1975 y, finalmente, por la última dictadura militar entre 1976 y 1983. El corolario fue la disolución de los institutos de la $\mathrm{FFyH}$, que, como ya dijimos, pasarían a conformar las áreas del Centro de Investigación de la Facultad de Filosofía y Humanidades (CIFFyH) en 1987.30

\section{Reflexiones finales}

En este artículo, me propuse describir, a partir de la experiencia de mis prácticas profesionales supervisadas, el proceso de conformación de la colección folklórica ubicada en el Museo de Antropología (FFyH-UNC). La perspectiva de biografía cultural de las cosas se aplicó tanto al proceso de conservación preventiva, para entender el estado actual de la materialidad de la colección, como al análisis de documentos y publicaciones producidos por los investigadores del Instituto de Antropología, Lingüística y Folklore entre 1941 y 1956, para poder comprender cuáles fueron las políticas institucionales $\mathrm{y}$, específicamente, qué criterios teóricos y metodológicos contaban a la hora de recopilar los materiales que hoy conforman la colección.

Según Mirta Bonnin, el desgranamiento de la colección folklórica comenzó alrededor de 1959-1960 y, en general, continuó durante años por distintas razones, entre las que se destacan, los traslados mal hechos y mal planificados, los problemas de infraestructura en las distintas sedes del Instituto y también la negligencia por parte de algunos miembros de la institución. En cuanto a la situación de la colección folklórica en el subsuelo del pabellón España, es posible observar cómo operó el concepto de depósito luego de la primera etapa de formación del acervo, descrito anteriormente. La colección se trasladó y se depositó ahí, sin generarse una política de cuidado de ese patrimonio, que, en ese momento, no era considerado como tal. Todos estos factores contribuyeron al deterioro y fragmentación de la colección luego de su primer traslado.

Considero que historizar la trayectoria de la colección folklórica es necesario para entender la historia de la Antropología en Córdoba, debido a que el desarrollo del Folklore como disciplina se constituye como un antecedente, una de las primeras formas de hacer Antropología en la provincia. A su vez, es importante destacar que, a partir de la investigación surgida en el marco de las prácticas, fue posible mitigar los efectos que la disociación de los materiales trajo aparejada, aportando además información capaz de ayudar a contextualizar los mismos teniendo en cuenta su trayectoria.

Finalmente, me gustaría agregar que podría pensarse al Folklore y sus sujetos como el otro constitutivo de la nación, ese otro interno sobre el cual pretendían erigir la nación los folkloristas del IALF, tal como se contextualizó anteriormente. En ese momento histórico, se planteaba que, por el desarrollo de la modernidad, los valores propios de la

30 A partir de esta situación, se creó un nuevo reglamento para el funcionamiento del Museo de Antropología, que quedó por fuera de esa reestructuración, y en el año 2002 abre sus puertas al público en su actual ubicación en la avenida Hipólito Yrigoyen 174.

Anuario de la Escuela de Historia Virtual - Año 11 - No 18 - 2020: pp. 46-68. ISSN: 1853-7049 
argentinidad se estaban perdiendo y se veía en los sujetos folklóricos la representación de esos valores que los folkloristas querían preservar y reproducir. La disolución de la identidad nacional podía pensarse como una posibilidad en la época, debido a las grandes olas de inmigrantes llegados al país y las migraciones internas masivas desde el campo a la ciudad, por lo cual, sus objetivos de investigación se centraban en la preservación y en la difusión necesaria para mantener ciertas tradiciones -inventadas diría Hobsbawm- que provenían del pasado y se encontraban en vías de desaparición, pero que se consideraban importantes para mantener la unidad nacional, la comunidad imaginada de la que hablaba Benedict Anderson.

\section{Fuentes}

Archivo del Museo de Antropología, Colección Folklórica, Caja "Fichas musicológicas"

Archivo del Museo de Antropología, Colección documental Serrano.

Archivo del Museo de Antropología, Correspondencia emitida al Rectorado 41-45.

\section{Bibliografía}

Anderson, B. (1993 [1983]). Comunidades imaginadas: Reflexiones sobre el origen y la difusión del nacionalismo. México: Fondo de Cultura Económica.

Blache, M. (1992). Folklore y nacionalismo en la Argentina. Su vinculación de origen y su desvinculación actual. Runa, 20 (1), 69-89.

Blache, M. y Dupey, A. M. (2007). Itinerarios de los estudios folklóricos en la Argentina. Relaciones de la Sociedad Argentina de Antropología, 32, 299-317.

Bonnin, M. (2007). La trama de las funciones museológicas en la gestión de las colecciones: el caso del Museo de Antropología (Universidad Nacional de Córdoba, Argentina) (Tesis de Maestría en Museología). Universidad Nacional de Costa Rica, Heredia.

Chamosa, O. (2012). Breve historia del folklore argentino (1920-1970): Identidad, política y nación. Buenos Aires: Edhasa.

De Carli, M. C. (2012). Los estudios folklóricos en el Instituto de Arqueología, Lingüística y Folklore "Dr. Pablo Cabrera" de la Universidad Nacional de Córdoba, 1941-1957 (Tesis de grado). Universidad Nacional de Córdoba, Córdoba.

Díaz, C. (2009). Variaciones sobre el ser nacional. Una aproximación sociodiscursiva al "folklore" argentino. Córdoba: Recovecos.

Hobsbawn, E y Ranger, T. O. (Eds.). (2002 [1983]). La invención de la tradición. Barcelona: Crítica.

Izeta, A. D. et al. (2017). Repositorio Institucional Digital Temático SUQUÍA. Museo de Antropología, Facultad de Filosofía y Humanidades. Universidad Nacional de Córdoba.

Kopytoff, I. (1991). La biografía cultural de las cosas: La mercantilización como proceso. En A. Appadurai (Ed.). La vida social de las cosas: perspectiva cultural de las mercancías (pp. 89-122). México: Grijalbo. 
68 | La conformación de la colección folklórica del Instituto de Antropología...

Lazzari, A. (2004). Antropología en el Estado: el Instituto Étnico Nacional (1946-1955). En M. Neiburg y M. Plotkin (Comps.). Intelectuales y expertos. La constitución del conocimiento social en la Argentina (pp. 203-229). Buenos Aires: Paidós.

Portilla Romero, C. (2014). La digitalización y la conservación preventiva como herramientas para el registro, exposición y almacenaje de obras sobre papel (Trabajo de fin de grado). Universitat Politècnica de València, Valencia.

Prats, Ll. (1997). Antropología y patrimonio. Barcelona: Ariel.

Vega, C. (1944). Panorama de la música popular argentina con un ensayo sobre la ciencia del folklore. Buenos Aires: Losada.

Viggiano Esaín, J. (1948). Escuela musicológica argentina. Córdoba: Instituto de Arqueología, Lingüística y Folklore "Dr. Pablo Cabrera".

Viggiano Esaín, J. (1969). Cancionero Popular de Córdoba, tomo I, Poesía tradicional. Coplas. Córdoba: Instituto de Estudios Americanistas, Universidad Nacional de Córdoba.

Para citar este artículo:

Cuevas, Agustín (2020). La conformación de la colección folklórica del Instituto de Antropología, Lingüística y Folklore (1941-1956) de la Universidad Nacional de Córdoba, Argentina. Anuario de la Escuela de Historia Virtual, 18, 46-68. 